\title{
Biological and mechanical enhancement of impacted allograft seeded with human bone marrow stromal cells: potential clinical role in impaction bone grafting
}

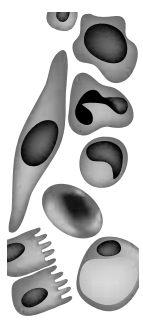

\author{
Benjamin JRF Bolland ${ }^{1}$, \\ KrisPartridge ${ }^{1}$, \\ Simon Tilley ${ }^{1}$, \\ Andrew MR New², \\ D ouglas G D unlop ${ }^{1}$ \& \\ Richard OC O reffol† \\ ${ }^{\dagger}$ Author for correspondence \\ ${ }^{1}$ B one \& Joint Research \\ Group, D evelopmental \\ $O$ rigins of $\mathrm{H}$ ealth and \\ D isease, U niversity of \\ Southampton, Southampton, \\ SO 16 6YD, UK \\ Tel.: +44 2380798502 \\ Fax: +44 2380796141 ; \\ E-mail: roco@soton.ac.uk; \\ www.mesenchymalstemcellsorg \\ 2 Bioengineering Science \\ Research Group, School of \\ Engineering Sciences, \\ U niversity of Southampton, \\ Southampton, \\ SO 16 6YD, UK
}

Keymords human allograft, human bone marrow stromal cells, impaction bone grafting

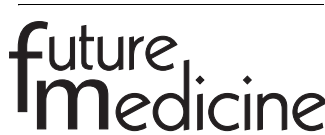

With the demographics of an aging population the incidence of revision surgery is rapidly increasing. Clinical imperatives to augment skeletal tissue loss have brought mesenchymal stem cells to the fore in combination with the emerging discipline of tissue engineering. Impaction bone grafting for revision hip surgery is a recognized technique to reconstitute bone, the success of which relies on a combination of mechanical and biological factors. The use of morsellized allograft is currently the accepted clinical standard providing a good mechanical scaffold with little osteoinductive biological potential. We propose that applying the principles of a tissue engineering paradigm, the combination of human bone marrow stromal cells (hBMSCs) with allograft to produce a living composite, offers a biological and mechanical advantage over the current gold standard of allograft alone. This study demonstrates that hBM SCs combined with allograft can withstand the forces equivalent to a standard femoral impaction and continue to differentiate and proliferate along the bony lineage. In addition, the living composite provides a biomechanical advantage, with increased interparticulate cohesion and shear strength when compared with allograft alone.

Each year in the UK there are over 50,000 primary hip replacement operations at a cost of $£ 250$ million. With an increasing aging population, this is set to rise to 65,000 by 2026 of which $30-50 \%$ will require subsequent revision surgery [1]. This is a significant orthopedic challenge due to extensive bone loss associated with revision surgery requiring reconstruction and regeneration of bone stock.

The technique of impaction bone grafting in the acetabulum was first introduced by Slooff and coworkers in Nijmegen, in the late 1970s [2]. The technique was introduced in the UK by Ling, Gie and colleagues in Exeter in 1987. Results from this center have shown excellent mid-term outcomes with $99 \%$ survival at 10 year average follow up in 226 patients with a femoral reoperation due to symptomatic aseptic loosening as the endpoint [3]. Other centers however have had a different experience. In Bristol, a group of 79 hip replacements followed up for just over 1 year, in whom impaction grafting of the femur had been performed, nine (11\%) showed evidence of massive subsidence [4]. This was defined as subsidence of over $10 \mathrm{~mm}$ and in all cases occurred in the first 3 months postoperatively. Six hips required subsequent re-revision. Interestingly, one hip was reported to have subsided to a position of stability. A series in Australia found similar subsidence values of $9 \mathrm{~mm}$ (range 2-37 mm) compared with cemented revisions at 24 months [5]. 0 ne problem with impaction grafting is that the decision of when the graft is suitably compacted is very subjective and this may explain the variation in results.

The fundamental aim is to achieve stability of an implant with the use of compacted morsellized bone graft and subsequent restoration of living bone stock by bony ingrowth. A commonly reported problem is subsidence of the stem within the femur, which can result despite vigorous impaction. The graft aggregate fails in shear and consequently studies based on basic soil mechanics have established techniques to improve the shear strength of impacted graft used in impaction bone grafting [6-8]. Shear strength of a granular aggregatelike bone graft depends on the internal friction $(\Phi)$, expressed as the angle at which the aggregate will slide, and interlocking of the particles (c), expressed as a stress. The frictional resistance varies in proportion with the normal (compressive) stress $(\sigma)$ produced by the load supported by the aggregate. The relationship between the parameters can be expressed by the Mohr Coulomb failure law $(\tau=c+\sigma \tan \Phi)$ 
which allows us to calculate shear strength of an aggregate. Using these principles the shear strength, interlocking particle cohesion and internal friction of bone graft aggregates of differing compositions can be compared.

M orsellized compacted allograft provides an excellent mechanical scaffold to support a prosthesis, provided good graft preparation and particle size grading [9], but is predominantly osteoconductive with no published evidence of osteoinductive capacity.

Bone marrow contains osteogenic progenitor cells that arise from multipotent mesenchymal stem cells. These cells exist postnatally, are multipotent and have the ability to give rise to the stromal lineages including bone, cartilage, muscle, tendon, ligament and fat [10]. The potential regeneration of tissues by seeding cells onto scaffolds ex vivo has led to the exciting and expanding discipline of tissue engineering [11,12]. H owever, the concept of using allograft as a clinical scaffold is not a new phenomenon. $\mathrm{H}$ istorical studies by Burwell using an animal model, demonstrated that bone allograft seeded with autogenous marrow as a composite graft resulted in considerably more new bone than either of the components of the graft transplanted separately [13]. This work however did not involve the isolation and expansion in vitro of osteoprogenitor subgroup from pure bone marrow. In addition the viability of osteoprogenitor cells to withstand the forces associated with a standard femoral impaction bone grafting remains to be established. The aim of this study was to determine if human bone marrow stromal cells (hBM SCs) seeded onto allograft, to produce a living composite, could survive the forces of impaction, and continue to differentiate and proliferate along the osteogenic lineage. In addition to the biological advantage provided by allograft augmentation with hBM SC S, we explored the potential improvement in mechanical properties the living composite may confer over impacted allograft alone.

\section{Methods}

Reagents, hardware \& software

Tissue culture reagents including $\alpha-M$ EM, fetal calf serum (FCS), ascorbate, dexamethasone and all staining agents were purchased from Sigma, Aldrich, UK unless otherwise stated. Cell Tracker Green $^{\text {m" }}$ CM FDA (5-chloromethyl-fluoescein diacetate) and Ethidium Homodimer-1 were purchased from M olecular Probes, Leiden, $N$ etherlands. Impaction cages, acrylic rings, bases and lids were kindly manufactured at Southampton University Bioengineering department and sterilized in $100 \%$ ethanol.

\section{Graft preparation}

$\mathrm{H}$ ighly washed morsellized allograft scaffolds were used in all studies obtained from fresh frozen femoral heads that had been stored at $-80^{\circ} \mathrm{C}$ for greater than 6 months. These had been retrieved with the consent of patients undergoing elective or traumatic hip surgery at Southampton General Hospital. Only tissue that would have been discarded was used, with the approval of the local ethics committee. Under sterile conditions in theater, unmarked femoral heads were defrosted by soaking in warm normal saline, followed by removal of all soft tissue, osteophytes and cartilage using bone nibblers and oscillating saw (Stryker, H owmedica, UK). The heads were cut into halves and milled using the Aesculap $3 \mathrm{~mm}$ bone mill. Previous analysis of a variety of bone mills currently in practice revealed the closest to optimum particle size and distribution (i.e., well graded bone graft mix) was produced from this mill [6], and was therefore used in this study. Milled bone graft was soaked in $6 \%$ hydrogen peroxide for $30 \mathrm{~min}$, removing all fat and marrow. The film of fat that collected on the fluid surface was removed along with the hydrogen peroxide. The graft was then washed repeatedly with normal saline ( $x 3)$, soaked in antibiotic/antimycotic solution for $24 \mathrm{~h}$, re-washed in phosphate buffer solution and left to stand in $\alpha-M$ EM prior to use. $10 \mathrm{~cm}^{3}$ aliquots of bone graft (volume of graft necessary prior to impaction to produce pellet of correct size) were separated into individual culture containers prior to seeding (seven samples per patient cell line, three for mechanical testing and four for biological analysis).

\section{Cell culture}

Bone marrow samples (six patients in total three women and three men, aged $74-88$ years, with a mean age of 80 years) were obtained from hematologically normal patients undergoing routine total hip replacement surgery again with the approval of the local hospital ethics committee. hBM SC s were harvested by repeatedly washing the marrow in $\alpha-M E M$, removing the washed cell population prior to centrifugation at $1100 \mathrm{rpm}$ for $5 \mathrm{~min}$ at $4^{\circ} \mathrm{C}$. The cell pellet was resuspended in $10 \mathrm{mls} \alpha-M$ EM and passaged through a $70 \mu \mathrm{m}$ filter. The cell fraction was then plated onto tissue culture flasks 
(size of which was dependent on yield from sample) and cultured in $\alpha-M$ EM and $10 \%$ FCS under osteogenic conditions (100 uM ascorbate-2-phosphate, and $10 \mathrm{nM}$ dexamethasone) and incubated at $37^{\circ} \mathrm{C}$ in $5 \% \mathrm{CO}_{2}$. First wash in PBS and media change occurred at day 6 and then repeated every 3-4 days. U pon confluence the cells were released using trypsin in EDTA, centrifuged and resuspended in media (containing $10 \%$ serum) and the total count using a hemocytometer determined. $2 \times 10^{6}$ cells were seeded onto each sample of allograft with the addition of media to ensure graft coverage. The sterile pots containing seeded allograft were placed on an agitator within the incubator for $4 \mathrm{~h}$ to optimize cell adherence prior to impaction. Only P1 cultured cells were used in all studies.

Impactor design

Previous studies using forceplate analysis have determined the total force imparted during a standard femoral impaction bone grafting to be equivalent to a $1.98 \mathrm{~kg}$ mass falling $65 \mathrm{~mm}$ onto a circular base plate $60 \mathrm{~mm}$ in diameter [14]. The apparatus was appropriately rescaled to an impactor with a $344 \mathrm{~g}$ mass and a drop height of $65 \mathrm{~mm}$ and a graft pellet $25 \mathrm{~mm}$ in diameter. D uring impaction and cell culture, the graft was contained in a graft chamber consisting of a base, ring and lid machined from cast acrylic rod. When assembled, the three components enclosed a cylinder of graft $25 \mathrm{~mm}$ in diameter and $10 \mathrm{~mm}$ high, a volume of $4.9 \mathrm{~cm}^{3}$.

\section{Scaffold impaction}

Impaction of seeded allograft was carried out as described by Dunlop and colleagues. Briefly, seeded scaffold was introduced into the top of the impactor in three equal portions to ensure even compaction. The weight was dropped 24 times from the given height at a rate of approximately $1 \mathrm{~Hz}$. The piston was then rotated (to prevent test material adhering to the base of the impactor) and removed. A further portion of graft was added and the process repeated, twice, so that the finished pellet received 72 impactions.

The impaction chamber design allowed the easy loading and unloading of the acrylic rings, used to contain the impacted graft. In addition, holes within the acrylic rings and in the base of the chamber itself allowed fluid but not particles to escape, so preventing pressure build which has a detrimental effect on the degree of impaction. After impaction and removal from the chamber, perforated acrylic discs were placed either side of the ring and held with a polyethylene clip. This allowed containment of the impacted graft without a compressive force. The contained impacted seeded allograft was transferred into a sterile polyethylene pot with $15 \mathrm{ml}$ of osteogenic media and incubated at $37^{\circ} \mathrm{C}$ in $5 \% \mathrm{CO}_{2}$. Allograft alone samples were prepared, impacted and cultured under identical osteogenic conditions as a control group. Samples were cultured for either 2- or 4-week periods, with washes in PBS and media changes every 3-4 days.

Analysis of cell viability

Samples from the periphery and centrally within the impacted aggregate were taken from each patient cell line at 2- and 4-week intervals and incubated with C ell Tracker Green and ethidium homodimer-1 (EH -I) for 45 min to label viable and necrotic cells. Confocal microscopy was performed on these samples using a Leica TCS SP2 laser scanning microscope and software.

DNA \& alkaline phosphatase-specific activity Separate samples were taken for quantitative biochemical analysis. The impacted allograft segments were dissected into equal sized quarters and then incubated with trypsin/EDTA $(0.05 \%)$ at $37{ }^{\circ} \mathrm{C}$ and $5 \% \mathrm{CO}_{2}$ interspersed twice with vigorous vortexing. $\mathrm{C}$ ells were collected by centrifugation at $13,000 \mathrm{rpm}$ for $10 \mathrm{~min}$ at $4{ }^{\circ} \mathrm{C}$, and then resuspended in $1 \mathrm{ml} 0.05 \%$ Triton X-100. Lysis was achieved by freezing-thawing and samples were stored at $\sim 20^{\circ} \mathrm{C}$ until assayed. Lysate was measured for alkaline phosphatase activity using p-nitrophenyl phosphate as substrate in 2-amino2-methyl-1-propanol alkaline buffer solution (1.5 M, pH 10.3 at $25^{\circ} \mathrm{C}$ [Sigma, Poole, UK]). DNA content was measured using PicoGreen according to manufacturer's instructions (M olecular Probes, Paisley, UK). Alkaline phosphatasespecific activity was expressed as nanomoles of p-nitrophenyl phosphate/h/ng D N A.

\section{Histological staining}

Samples were fixed in 95\% ethanol, decalcified in EDTA/Tris, processed and paraffin embedded. Cell adherence and proliferation was confirmed with hemotoxylin and eosin $(H \& E)$ staining. Immunohistochemistry for Type 1 collagen and bone sialoprotein (BSP) were performed to confirm cell differentiation along the osteogenic lineage. 
Biomechanical testing

The shear strength of all test materials was determined using a Cam shear tester (manufactured at the School of Engineering Sciences, U niversity of Southampton). This device enables the mechanical behavior of particulate materials in combined normal and shear loading to be characterized. It consists of a fixed upper ring and a mobile lower ring. The normal load was applied by loading weights onto a plunger running in a linear bearing and resting on top of the test material. The normal load was applied $5 \mathrm{~min}$ prior to the shear to allow the sample to settle. During the test the mobile lower ring was driven by an hydraulic actuator (Instron Ltd, Bucks, UK) at a constant rate of displacement of $1.2 \mathrm{~mm} / \mathrm{min}$ relative to the upper ring, shearing the test sample. The force required to shear the sample and the displacement of the lower ring were recorded using the load and displacement sensors incorporated into the actuator.
Three compressive loads (50, 150 and $250 \mathrm{~N}$ ) were used on separate samples. These loads generated compressive stresses $(102,306$ and $509 \mathrm{kPa}$ respectively) representative of the lower range of normal physiological stresses. This generated a family of stress-strain curves for each cell line $(n=3)$ with controls $(n=3)$ at two time intervals from which the M ohr Coulomb failure envelope curve was plotted and the shear strength, interlocking particle cohesion and friction angle derived.

\section{Micro CT analysis}

Using X-Tek micro CT unit (Xtek Systems Ltd, $H$ ertfordshire, UK), 4-week samples from each cell line were imaged at approximately 55 micron resolution. 3D reconstructions using $\mathrm{V}$ tech studio MAX 1.2.1 (Volume Graphics $\mathrm{GmbH}, \mathrm{H}$ eidelberg, G ermany) provided a qualititative and quantitative comparison of aggregate density.

\section{Figure 1. Confirmation of cell viability with ethidium homodimer/Cell Tracker Green staining at 2 w eeks from (A) periphery and (B) center of the allograft/hBMSC composite (x10), and 4 weeks; (C) periphery and (D) center of the allograft/hBMSC composite $(x 10)$.}
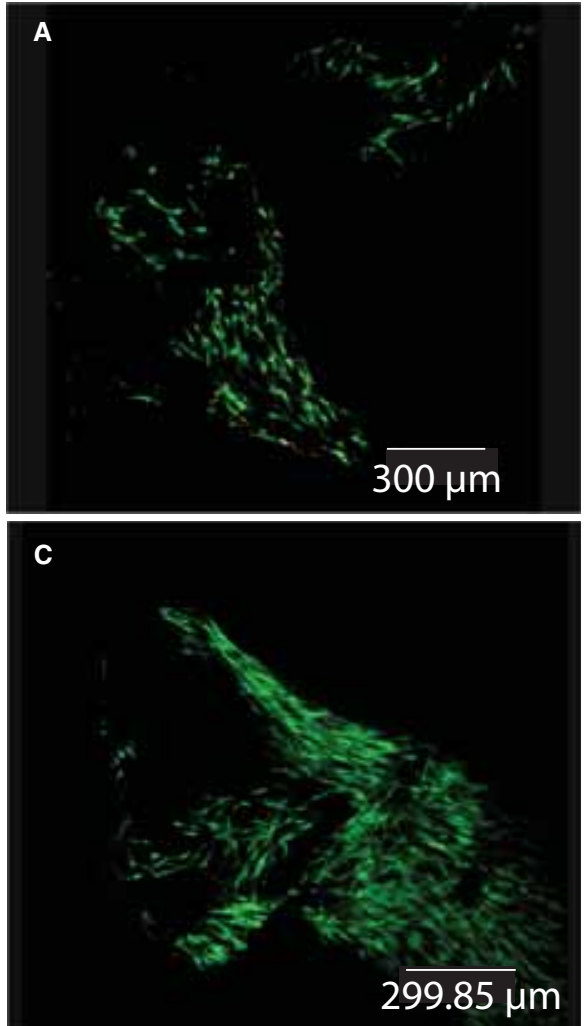

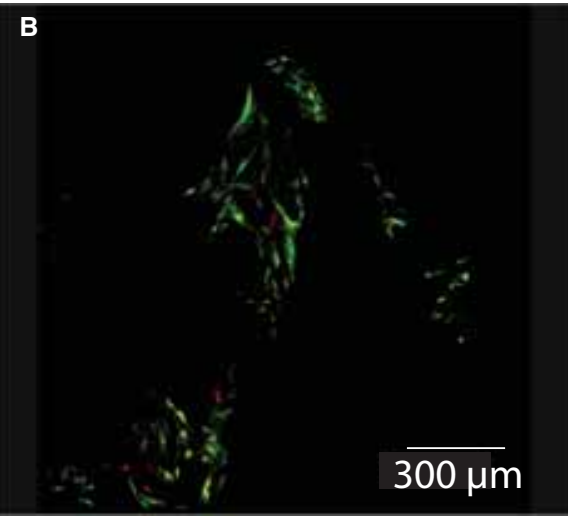

D

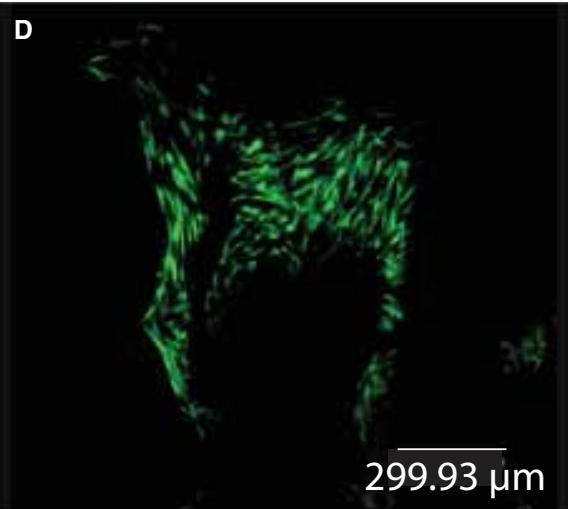




\section{Statistics}

A general linear model with shear strength as the dependent variable was fitted with axial stress as an independent variable and a categorical term for treatment. SPSS for Windows, Version 14 (SPSS UK, Surrey, U K) was used to conduct the analysis to establish whether there was a linear relationship and whether there was a difference between the control and study groups at both time points.

\section{Results}

Cell viability

The survival of cells on impacted allograft was evidenced by fluorescence staining following incorporation of the $\mathrm{C}$ ell Tracker green probe into viable cells and negligible ethidium homodimer-1 staining; a marker of cell death. (Figure1A-D). In addition, there was evidence of cell growth and proliferation with increased number of cells staining as observed using the
Cell Tracker green probe within the 4 week samples when compared to 2 week samples (Figure1A-D).

DNA \& alkaline phosphatase-specific activity Examination of D NA content as a marker of cell proliferation, and alkaline phosphatase as a marker of the osteoblast phenotype demonstrated an increase in the DNA content (2.5-5.3 $\times 10^{3} \mathrm{ngD} \mathrm{N}$ A/quarter) and specific alkaline phosphatase activity $(0.86-1.48 \mathrm{nM}$ $\mathrm{pN} P P / \mathrm{h} / \mathrm{ngD} \mathrm{N}$ A) from impacted allograft seeded with $\mathrm{hBM}$ SC $\mathrm{s}$ compared with allograft alone at 2 weeks. At 4 weeks there was evidence of continued cell viability and proliferation with ongoing rise in DNA content (13.0-21.1 $\times 10^{3} \mathrm{ngD} \mathrm{N}$ A/quarter sample) but was associated with a concominant fall in specific alkaline phosphatase activity $(0.30-0.55 \mathrm{nM}$ $\mathrm{pN} \mathrm{PP/h/ng} \mathrm{DN} \mathrm{A)} \mathrm{(Figre} \mathrm{2,} 3$ \& 4D). D N A content and specific alkaline phosphatase activity

\section{Figure 2. Mean DNA content from three patient cell lines at 2- and 4-w eek time intervals $(n=4)$.}

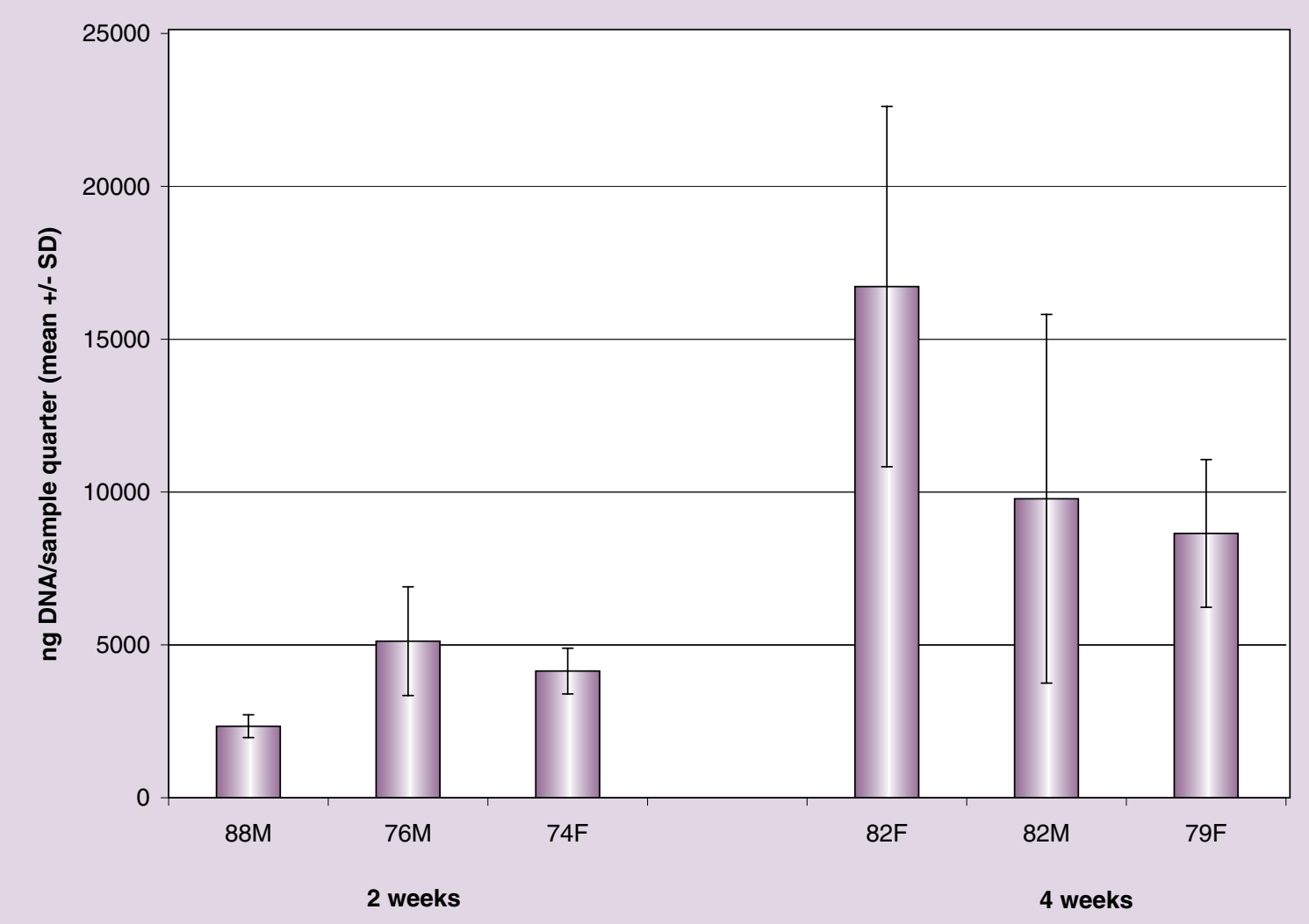

An increase in DNA content from 2 to 4 weeks represented ongoing cell survival and proliferation. 
Figure 3. Specific alkaline phospatase activity from three patient cell lines at 2- and 4-w eek intervals $(n=4)$, demonstrating a fall off in activity with time.

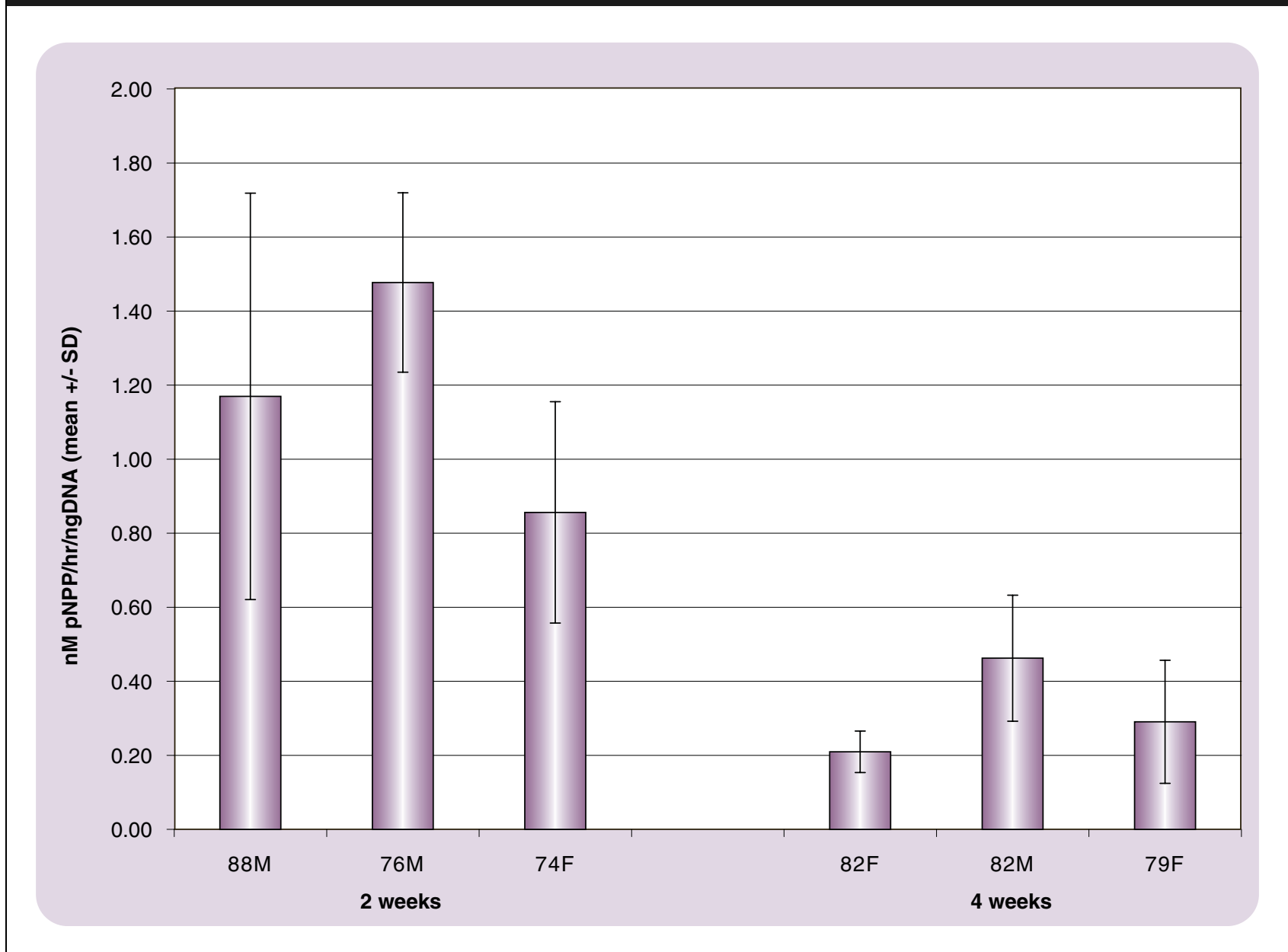

values from allograft alone were negligible at 2 and 4 weeks and were subtracted from the values obtained from the allograft/hBM SC s samples.

Histology \& immunocytochemistry

$H \& E$ staining confirmed cell presence and adherence (Figure $\mathbf{4 A} \& \mathbf{B}$ ) with an apparent propensity for the marrow stromal cells to adhere to the fibrous connective tissue layer that remained adherent to the allograft after washing. Collagen Type 1 and BSP immunostaining confirmed expression of the osteogenic phenotype of the stromal cells with increased expression observed at 4 weeks (Figure4E-K).

\section{Shear testing}

Examination of shear strength showed a linear increase with compressive stress $\left(R^{2}>0.99\right)$ for all groups and time intervals, indicating that the grafts satisfied the Mohr Coulomb failure law (Figre 5\& 6). Interparticulate cohesion (shear strength in the absence of compressive load) and shear strength values, were significantly greater in hBM SC/allograft samples compared to allograft alone at both 2 and 4 weeks $(n=3$, $p<0.001$ ) (Table 1). There was no difference in friction angle at either time point.

Impacted allograft seeded with hBM SC s and cultured for 2 weeks resulted in higher particle interlocking. The friction angle, which is determined by the particle grading of the aggregate was unchanged with the addition of hBM SCs. This confirmed similar particle-size distribution between the two groups, and was to be expected as all allograft was prepared using the same bone mill. However as a result of increased particle interlocking without any subsequent change in friction angle, samples with cultured hBM SC s had higher shear strength at all compressive forces $(p<0.001)$ (Figure 5). Similar results were also seen at 4 weeks (Figre6) but with no further significant rise in either particle interlocking or 


\section{Figure 4. Histological and immunocytochemical staining of allograft/hBMSC and allograft alone samples.}

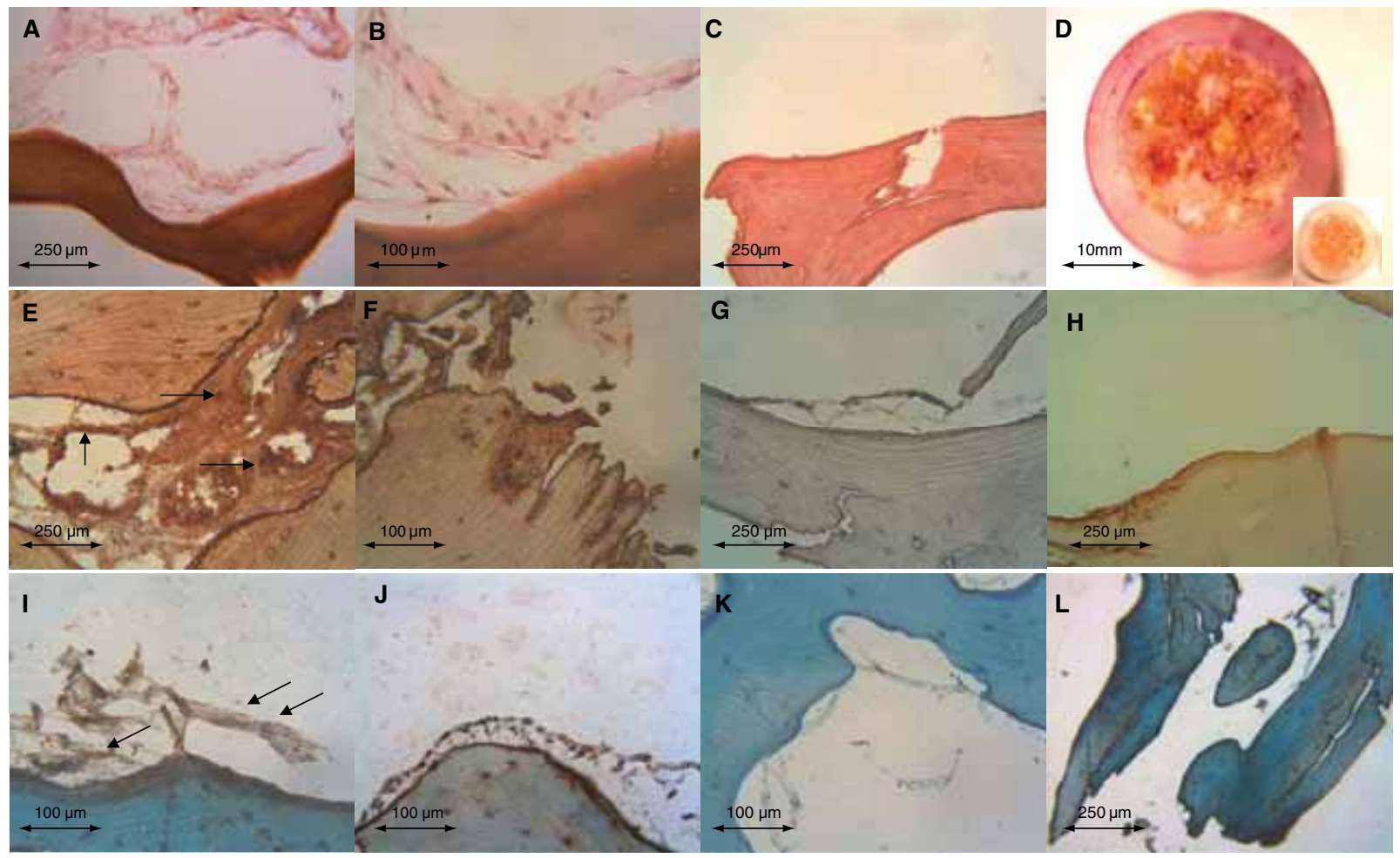

Hematoxylin and Eosin staining at(A) x10 and (B) x25 magnification demonstrating cells adherent to the allograft surface (arrows) and (C) contrasting bare surface of allograft alone (x10). (D) Alkaline phosphatase positive surface staining on allograft/hBM SC sample (insert: allograft alone). Collagen type 1 staining of allograft/hBM SC composite at (E) x10 and (F) X25 magnification demonstrating the presence of cells with surrounding increased staining (arrows), when compared to $(G)$ negative control $(x 10)$ and $(H)$ allograft alone (x10). Increased positive staining for Bone Sialoprotein surrounding a palisade of cells adherent to allograft at $(I, J) \times 25$ magnification compared with (K) negative control (x10) and (L) allograft alone.

shear strength $(p=0.699)$. The shear strength values observed were comparable to those reported by Dunlop and colleagues (range $208-282 \mathrm{kPa}$ )

\section{Micro CT}

Q uantitative density analysis confirmed no statistical difference in mean aggregate density, between the two groups at 4 weeks. Critically, micro CT analysis confirmed allograft and allograft/hBM SC s had similar particulate grading and were exposed to similar degrees of impaction.

\section{Discussion}

This study has demonstrated both biochemically and histologically that hBM SC s can adhere to and proliferate on highly washed morsellized bone graft and, significantly, can withstand the forces equivalent to a standard femoral impaction bone grafting. In addition, the living composite of impacted allograft and hBM SCs, demonstrates a significant mechanical advantage with increased interparticulate cohesion and shear strength at 2 and 4 weeks when compared with allograft alone.

Since the evolution of impaction bone grafting, research has focused on methods to improve the mechanical and to a lesser extent biological characteristics of compacted morsellized allograft. Areas that have been investigated have included particulate grading and rinsing $[6,15]$ of the graft, mechanical differences in free dried irradiated or fresh frozen [16] graft, the effect of bone substitutes [17-19] and the augmentation of graft with osteoinductive factors [20-22]. 0 ften the outcomes have shown an improvement in one of the characteristics (either mechanical or biological) but with a worsening of the other. M orsellized allograft presently remains the gold standard for use in impaction bone grafting. The preparation of this graft is integral to the success of the 
Figure 5. Mohr Coulomb failure envelopes at 2-week time interval from allograft/hBMSCs composite and allograft alone, showing regression analysis trend lines and SD error bars.

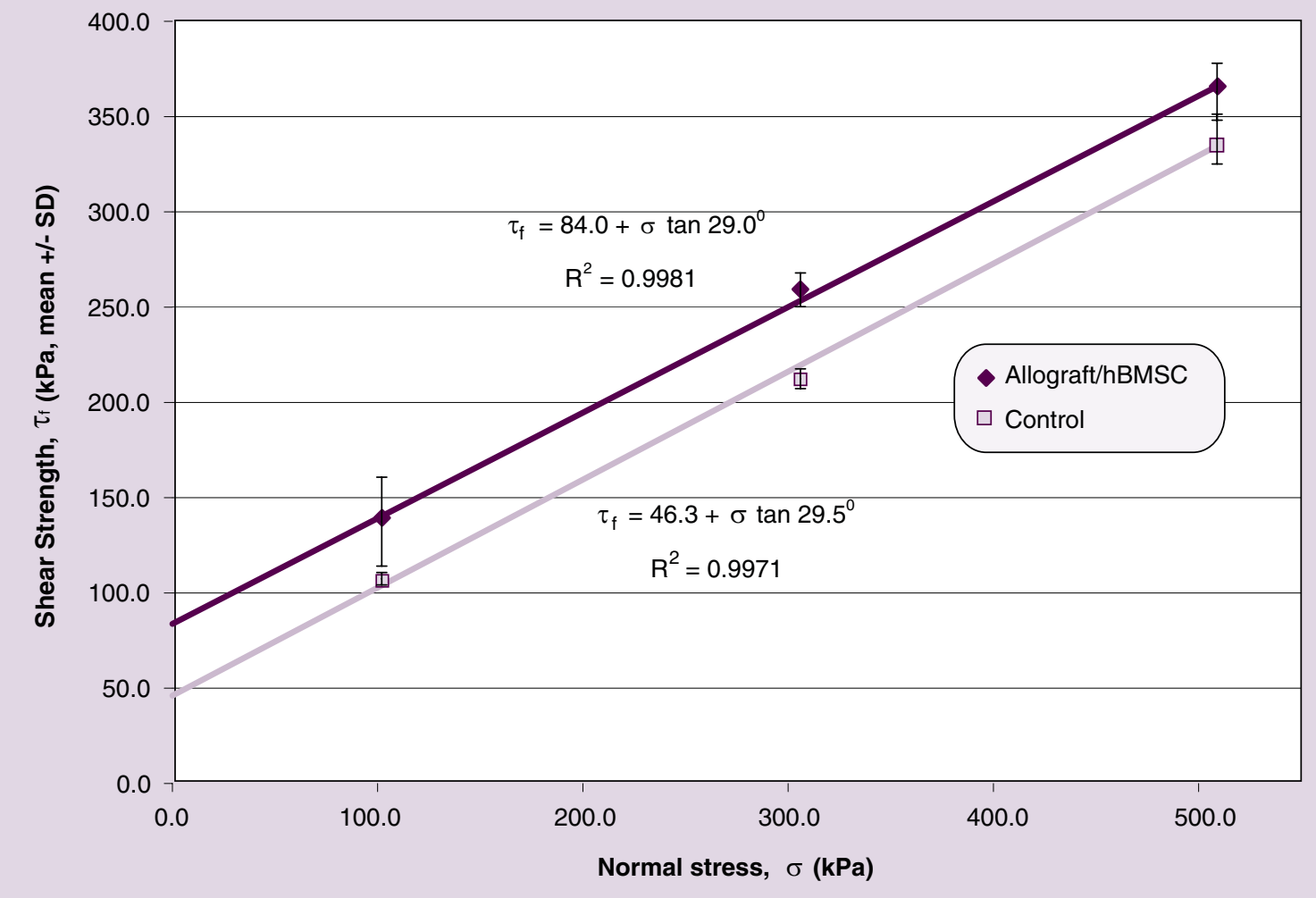

procedure. Studies have revealed that a well graded mix (proportions of various particle sizes and range) can optimize mechanical strength. In this study the grading of the mixes was identical in both groups, and both were subjected to the same impaction force (Figre7) with the only difference being the presence of hBM SC s. Since the friction angle of aggregates is dependent on particle size distribution we would not expect to see a difference in this angle between the two groups. The increase in shear strength that was observed in the living composite grafts is therefore directly attributable to the increased cohesion between the particles, and has important clinical implications. $M$ echanical stability is essential to allow early weight bearing, which is important in loading and stimulation of the graft with possible faster graft incorporation [23]. The increased shear strength provided by an allograft/hBM SC s composite could allow not only early mobilization of our patients but also lead to improved graft incorporation.
Although these results are extremely encouraging, caution must be advocated in advance of validation of mechanical enhancement in an in vivo model. The balance between bone resorption and bone regeneration normal seen in fracture healing (and graft incorporation) may be altered when the living composite is subjected to loading and a response from the hosts own cells. This will need to be established to ensure that the augmentation of allograft with hBM SCs does not result in a possible accelerated bone resorption prior to bone regeneration, with consequent aseptic loosening and implant failure.

Further optimization of mechanical performance along with offloading the al ready stretched demand on banked allograft, has been shown by the addition of bone substitutes $[18,19,24]$. These bone substitutes alone however do not add any osteoinductive biological enhancement to the aggregate. In this study the addition of hBM SCs provided osteoinductive potential, confirmed with initial cell viability and ongoing proliferation along a bony lineage from 2 to 
Figure 6. Mohr Coulomb failure envelopes at 4-week time interval from allograft/hBMSCs composite and allograft alone, showing regression analysis trend lines and SD error bars.

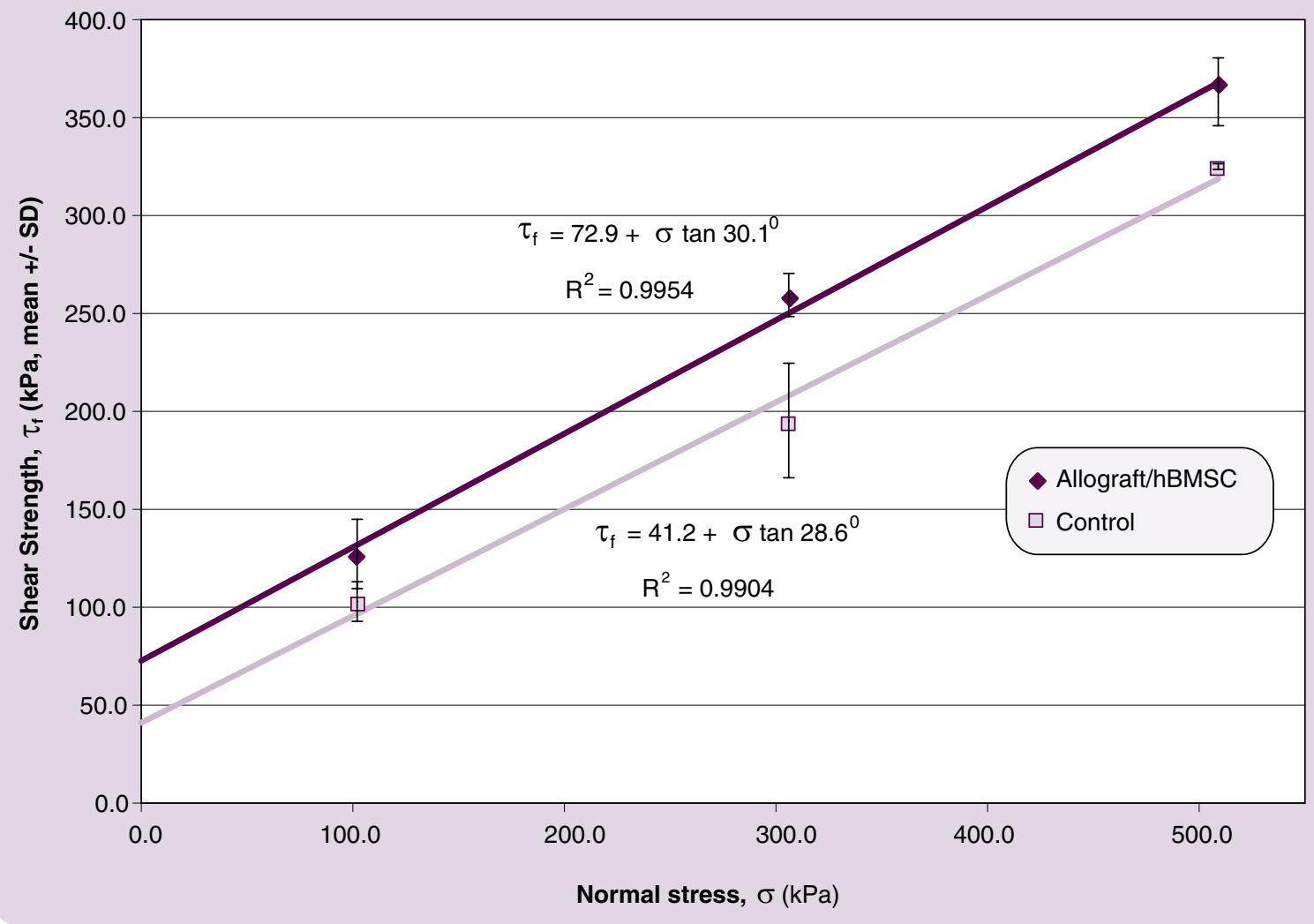

4 weeks (Figure2), as well as an improvement in aggregate shear strength and particulate cohesion when compared to allograft alone. Future work in the group is centered on the evaluation of bone substitutes and polymers with marrow

stromal cells and enriched mesenchymal stem cell populations to enhance osteoconductivity, osteoinductivity and osseointegration potential to the al ready established mechanical advantage they provide.

Table 1. Comparison of interparticulate cohesion, aggregate angle and shear strength values of allograft/hBMSCs and allograft alone $(n=3)$ samples taken at 2 and 4-w eek time intervals.

\section{Interlocking \\ (kPa)}

\section{Week 2}

Allograft \& hBMSCs

Allograft alone

84.0

72.9

41.2

Allograft \& hBMSCs Allograft alone

\section{Friction angle \\ (deg)}

29.0

29.5

30.1

28.6
Shear Strength ${ }^{\dagger}$ (kPa)

278

A general linear model demonstrated a significant difference between allograft alone and allograft and human bone marrow stromal cells (hBMSCs) at both 2 and 4 weeks ( $n=3, p<0.001)$. There was no statistical difference in allograft and hBMSC groups cultured for either 2 or 4 weeks $(n=3, p=0.669)$.

tThe values are given as $\mathrm{kPa}$ at $\sigma=350 \mathrm{kPa}$. 

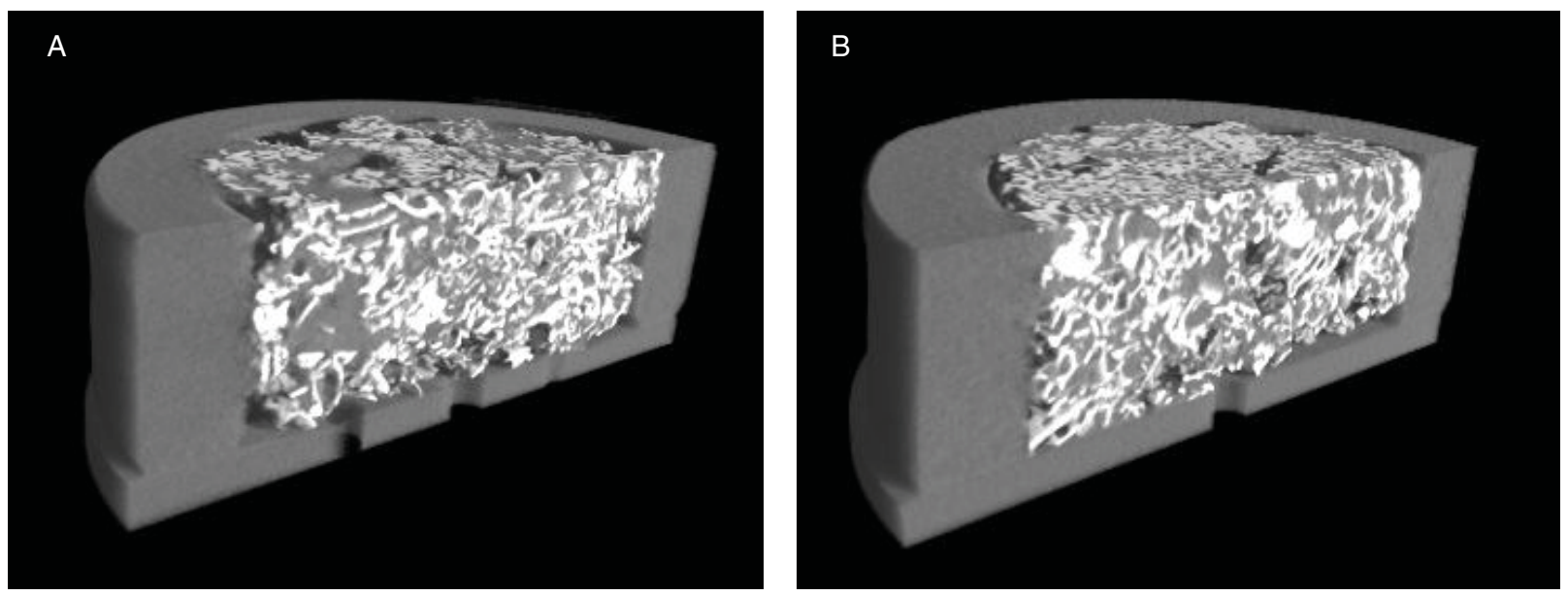

Allograft remains a potential source of retained immunogenicity (and disease transmission) - a risk that may be reduced by the action of washing $[6,15,25]$. H owever, allograft contains important growth factors and cytokines that encourage bone ingrowth and bone formation to replace the morsellized graft. In this study the graft preparation, involving multiple hydrogen peroxide and saline washes, ensured extensive removal of fat and bone marrow as confirmed on histological analysis (Figre 4C, inst) optimizing mechanical stability and minimizing immunogeneic load. The potential loss of key osteoinductive agents from successive washing protocols would appear to be compensated by the marrow

\section{Executive summary}

- Impaction bone grafting using morsellized allograft is the current gold standard to deal with loss of bone stock in revision hip surgery.

- Allograft provides mechanical support but offers little osteoinductive biological potential.

- Mesenchymal populations containing stem cells exist postnatally, are multipotent and have the ability to give rise to the stromal lineages (bone, cartilage, muscle, tendon, ligament and fat)

- Human bone marrow stromal cells seeded onto allograft results in the formation of a living composite capable of withstanding the forces equivalent to a standard femoral impaction and, under osteogenic conditions, differentiate and proliferate along the osteogenic lineage.

- In addition to the biological factors, the living composite graft has a biomechanical advantage over the allograft alone.

- Success of a synthetic scaffold within this paradigm would have implications in reducing the demand of dwindling stocks of banked allograft.

- The therapeutic implications of such composites auger well for orthopedic applications. stromal cells, which post impaction continue to proliferate and differentiate along the osteogenic lineage as evidenced by a rise in DNA content and specific alkaline phosphatase activity. Thus a highly washed, well graded aggregate seeded with hBM SC s enhances both mechanical and biological potential. Further reduction in the immunogeneic load and risk is provided by the use of freeze dried irradiated bone. It is currently debatable whether this form of preparation is detrimental or indeed enhances mechanical strength $[16,26]$. Either way the improved shear strength from proliferating hBM SC $s$ in combination with a scaffold without the potential for disease transmission or immunological complications is an attractive alternative to the current gold standard.

The translation of tissue engineering concepts into clinical practice will provide enormous input into the field of bone regeneration. Impaction bone grafting is an example of where currents concepts could augment and change clinical practice. This study has demonstrated that hBM SC s seeded onto allograft remain viable after impaction, proliferate and confer mechanical advantage over allograft alone. These changes resulting in enhancement of biological and mechanical properties of bone graft within impaction bone grafting have implications for translation and future change in orthopedic practice in an increasing aging population.

\section{Future perspective}

Bone substitutes have shown to be a useful adjuvant in impaction bone grafting, provid- 
ing potential mechanical advantage and offloading the already excess demand on banked allograft. As the scaffolds improve, and as long as a biological and mechanical advantage can be shown over the current gold standard, the routine use of allograft alone will no longer be indicated. The paradigm described could be applied to synthetic grafts to ascertain their suitability in the field of impaction bone grafting. Further small animal studies are required and if reciprocal encouraging biological and mechanical enhancement are observed this will have significant implications to a future change in clinical practice.

\section{Acknowledgements}

Wewould liketo thank Stryker U K for ther kind support of $\mathrm{Mr}$ Ben Boll and and $\mathrm{M} r$ Simon Tilley during ther timein research and members of the Bone \& Joint Research Group for many helpful discussions. We would like to thank D r SP Gopal M adabhushi, D epartment of Engineering, University of Cambridge for his expert adviceand opinion in this study in the fiedd of soil mechanics, and M r S H arris, D epartment of M edical Statistics, University of Southampton, for the statistical analysis The monodonal antibody to typel collagen was a generous gift from D r Larry Fisher ( $N$ ational Insitutes of $\mathrm{H}$ ealth, Bethesda, M D, USA). This work was supported by grants from the Biotechnological and Biological Sciences Research Council (BBSRC) and Engineering and Physical Sciences Research Coundil (EPSRC).

\section{Bibliography}

1. Spector $\mathrm{M}$ : Biomaterial failure. O rthop. Clin. N orth Am. 23(2), 211-217 (1992).

2. Slooff TJ, H uiskes R, van HJ, Lemmens AJ: Bone grafting in total hip replacement for acetabular protrusion. Acta O rthop. Scand. 55(6), 593-596 (1984).

3. H alliday BR, English H W, Timperley AJ, Gie GA, Ling RS: Femoral impaction grafting with cement in revision total hip replacement. Evolution of the technique and results. J. Bone Joint Surg. Br. 85(6), 809-817 (2003).

4. Eldridge JD , Smith EJ, H ubble M J, W hitehouse $S L$, Learmonth ID : M assive early subsidence following femoral impaction grafting. J. Arthroplasty 12(5), 535-540 (1997).

5. Sharpe $P$ : Impaction grafting or cement alone for femoral revision hip replacement. Conference proceedings. AN ZORS; Sydney, Australia (1998).

6. D unlop D G, Brewster NT, M adabhushi SP, U smani AS, Pankaj P, H owie CR: Techniques to improve the shear strength of impacted bone graft: the effect of particle size and washing of the graft. J. Bone Joint Surg. Am. 85-A(4), 639-646 (2003).

7. Lambe W RV: Soil M echanics - SI Version. John Wiley \& Sons, London, UK (2006).

8. Smith $\mathrm{GN}$ : Elements of Soil M echanics. 6th Edition. Blackwell Science, O xford, UK (2006).

9. M alkani AL, Voor M J, Fee KA, Bates CS: Femoral component revision using impacted morsellised cancellous graft. A biomechanical study of implant stability. J. Bone Joint Surg. Br. 78(6), 973-978 (1996).
10. O reffo RO, Cooper C, M ason C, Clements M : M esenchymal Stem cells: Lineage, plasticity and skeletal therapeutic potential. Stem Cell Rev. 1(2), 169-178 (2005).

11. Langer $R$ Vacanti JP: T issue engineering. Science 260(5110), 920-926 (1993).

12. Bianco P Robey PG : Stem cells in tissue engineering. $N$ ature 414(6859), 118-121 (2001).

13. Burwell RG : Studies in the transplantation of bone. VII. the fresh composite homograftautograft of cancellous bone; an analysis of factors leading to osteogenesis in marrow transplants and in marrow-containing bone grafts. J. Bone Joint Surg. Br. 46110-46140 (1964).

14. Brewster NT, Gillespie WJ, H owie CR, $M$ adabhushi SP, U smani AS, Fairbairn DR: $M$ echanical considerations in impaction bone grafting. J. Bone Joint Surg. Br. 81(1), 118-124 (1999).

15. van der $D S$, Weernink $T$, Buma $P$, Aspenberg P, Slooff TJ, Schreurs BW: Rinsing morselized allografts improves bone and tissue ingrowth. Clin. Orthop. Relat. Res (408), 302-310 (2003).

16. Cornu O, Bavadekar A, Godts B, Van TJ, D elloye $C$, Banse $X$ : Impaction bone grafting with freeze-dried irradiated bone. Part II. Changes in stiffness and compactness of morselized grafts: experiments in cadavers. Acta O rthop. Scand. 74(5), 553-558 (2003).

17. Blom AW, Cunningham JL, H ughes $G$ et al.: The compatibility of ceramic bone graft substitutes as allograft extenders for use in impaction grafting of the femur. J. Bone Joint Surg. Br. 87(3), 421-425 (2005).

18. Fujishiro $\mathrm{T}, \mathrm{N}$ ishikawa $\mathrm{T}, \mathrm{N}$ iikura $\mathrm{T}$ et al.: Impaction bone grafting with hydroxyapatite: increased femoral component stability in experiments using Sawbones. Acta O rthop. 76(4), 550-554 (2005).

19. van $\mathrm{H}$ aaren $\mathrm{EH}$, Smit $\mathrm{TH}$, Phipps $\mathrm{K}$, Wuisman PI, Blunn G, H eyligers IC: Tricalcium-phosphate and hydroxyapatite bone-graft extender for use in impaction grafting revision surgery. An in vitro study on human femora. J. Bone Joint Surg. Br. 87(2), 267-271 (2005).

20. Jeppsson C, Astrand J, Tagil M , Aspenberg P: A combination of bisphosphonate and BM $P$ additives in impacted bone allografts. Acta 0 rthop. Scand. 74(4), 483-489 (2003).

21. H eliotis M , Tsiridis EE: Fresh frozen bone in femoral impaction grafting: can developments in bone regeneration improve on this? M ed. H ypotheses 57(6), 675-678 (2001).

22. Tagil M, Jeppsson C, Aspenberg P: Bone graft incorporation. Effects of osteogenic protein- 1 and impaction. Clin. O rthop. Relat. Res. (371), 240-245 (2000).

23. Toms AD, Barker RL, Jones RS, Kuiper JH : Impaction bone-grafting in revision joint replacement surgery. J. Bone Joint Surg. Am. 86-A (9), 2050-2060 (2004).

24. Blom AW, Cunningham JL, H ughes $G$ et al.: The compatibility of ceramic bone graft substitutes as allograft extenders for use in impaction grafting of the femur. J. Bone Joint Surg. Br. 87(3), 421-425 (2005).

25. Bonfiglio M, Jeter W S: Immunological responses to bone. Clin. Orthop. Relat. Res 8719-8727 (1972).

26. Cornu O, BanseX, D ocquier PL, Luyckx S, D elloye C: Effect of freeze-drying and gamma irradiation on the mechanical properties of human cancellous bone. J. Orthop. Res. 18(3), 426-431 (2000). 